Para citar este artículo: Campos Pellanda, E., Fagundes Pase, A., Bisso Nunes, A. C., Streck, M., Ramos de Souza, D., \& Mércio Pereira, I. (2018). Comunicação e mobilidade: proposta de procedimento metodológico para o entendimento da audiência mobile através de um estudo de caso do UBILAB/PUCRS. Anuario Electrónico de Estudios en Comunicación Social "Disertaciones", 12(1), 43-58. Doi:

\title{
COMUNICAÇÃO E MOBILIDADE: PROPOSTA DE PROCEDIMENTO METODOLÓGICO PARA O ENTENDIMENTO DA AUDIÊNCIA MOBILE ATRAVÉS DE UM ESTUDO DE CASO DO UBILAB/PUCRS
}

Communication and Mobility: Proposed Methodological Procedure for the Understanding of the Mobile Audience through a Case Study of UBILAP/PUCRS

Comunicación y movilidad: propuesta de procedimiento metodológico para el entendimiento de la audiencia móvil a través de un estudio de caso de UBILAB/PUCRS

Eduardo Campos Pellanda, Pontifícia Universidade Católica do Rio Grande do Sul (PUCRS), Brasil eduardo.pellanda@pucrs.br

André Fagundes Pase, Pontifícia Universidade Católica do Rio Grande do Sul (PUCRS), Brasil afpase@pucrs.br

Ana Cecília Bisso Nunes, Pontifícia Universidade Católica do Rio Grande do Sul (PUCRS), Brasil ana.nunes@pucrs.br

Melissa Streck, Pontifícia Universidade Católica do Rio Grande do Sul (PUCRS), Brasil mstreck@gmail.com 
Daniele Ramos de Souza, Pontifícia Universidade Católica do Rio Grande do Sul (PUCRs), Brasil danieleramosdesouza@gmail.com

Isabella Mércio Pereira, Pontifícia Universidade Católica do Rio Grande do Sul (PUCRS), Brasil isamerciopereira@gmail.com

Recebido: 15 de setembro de 2017

Aprobado: 5 de junho de 2018

\section{RESUMO}

Esta investigação tem como objetivo o entendimento de uso e contexto da comunicação móvel. A observação de comportamentos e usos da audiência de dispositivos móveis em tempo real, um objetivo peculiar de pesquisa, demandou a criação de uma metodologia de estudo diferenciada, sobretudo na combinação de estratégias em virtude da sua natureza. Isto ocorre tanto no sentido técnico, pelo software utilizado para captura, bem como nos aspectos humanos, pois também houve diálogo com participantes dispostos a utilizar de forma natural um aparelho monitorado. Isto foi realizado sem que os hábitos de uso fossem corrompidos, pois os usuários estavam cientes do processo. Nesta primeira versão do método, foi desenvolvido um software de registro e totalização de dados de 17 aparelhos semelhantes. As informações foram utilizadas, posteriormente, na formulação de entrevistas em profundidade, que resultaram em representações gráficas da intensidade de uso de determinadas aplicações conforme o momento do dia. 0 procedimento foi validado durante 60 dias e demonstrou ser uma forma de compreender hábitos de uso do smartphone, assim como suas peculiaridades, ao passo que permitiu ir até os limites do sistema operacional para monitoramento e dentro do escopo da pesquisa em Comunicação.

Palavras-chave: mobilidade, comunicação móvel, metodologia, método, comportamento do usuário.

\section{ABSTRACT}

This research aims to understand the use and context of mobile communication. The observation of behaviors and uses of the audience of mobile devices in real time, a peculiar research, demanded the creation of a different methodology, mainly in the combination of strategies by the virtue of their nature. This occurs both in the technical sense, by the software used for data capture, and in human aspects, as there was also dialogue with participants willing to use a monitored device. This process occurred without corrupting the usage habits, as users were aware of the process. In this first version of the method, software was developed for recording and totalizing data from 17 similar devices. Later, the information was used to formulate in-depth interviews, which resulted in graphic representations of the intensity of use of certain applications according to the time of day. The procedure was validated during 60 days and 
showed to be a way to understand habits of use of the smartphone, while allowing to reach the limits allowed by the system for monitoring and within the scope of the research in communication.

Keyword: Mobility, mobile communication, methodology, method, user behavior.

\section{RESUMEN}

Esta investigación tiene como objetivo el entendimiento de uso y contexto de la comunicación móvil. La observación de comportamientos y usos de la audiencia de dispositivos móviles en tiempo real, un objetivo peculiar de investigación, requirió la creación de una metodología de estudio diferenciada, especialmente en la combinación de estrategias en virtud de su naturaleza. Esto ocurre tanto en el sentido técnico, tanto por el software utilizado para captura, como en los aspectos humanos, pues también hubo diálogo con participantes dispuestos a utilizar de forma natural un aparato monitoreado. Esto fue realizado sin que los hábitos de uso fuesen corrompidos, pues los usuarios estaban conscientes del proceso. En esta primera versión del método, fue desarrollado un software de registro y totalización de datos de 17 aparatos semejantes. Las informaciones fueron utilizadas, posteriormente, en la formulación de entrevistas en profundidad, que resultaron en representaciones gráficas de intensidad de uso de determinadas aplicaciones de acuerdo al momento del día. El procedimiento fue validado durante 60 días y demostró ser una forma de comprender hábitos de uso del smartphone, así como sus peculiaridades, mientras que permitió ir hasta los límites del sistema operacional para monitoreo y dentro del alcance de la investigación en Comunicación.

Palabras clave: movilidad, comunicación móvil, metodología, método, comportamiento del usuario.

\section{Introdução}

Em 2017, o IPhone completou 10 anos de existência. O aparelho tornou-se símbolo de uma era de comunicação móvel, cuja comunicação não ocorre utilizando somente a fala, apesar de ser realizada através de um telefone celular. Ao longo dos anos, marcas e sistemas operacionais surgiram com novas funções e possibilidades, aproximando o público de particularidades e nomes próprios que influenciam na forma como dialogam com seus pares e, sobretudo, o mundo.

Este constante movimento resulta em uma recombinação constante de estratégias de investigação. Se a comunicação por si só permite aproximações puramente textuais como a Análise de Conteúdo (Bardin, 2011) ou variações da etnografia tradicional, como a etnografia (Kozinets, 2009). Pesquisadores como Fragoso, Recuero \& Amaral (2011) observaram estas transformações, assim como Rogers (2013). 


\section{DISERTACIONES}

ESTUDIOS

Comunicación y dispositivos móviles

ISSN: $1856-9536$

Doi:

Volumen 12, Número 1 / Enero-junio 2019

Versión PDF para imprimir desde

http://revistas.urosario.edu.co/index.php/disertaciones

Porém, este espaço é diferente de outros, pois combina um uso portátil como observado no rádio com o digital e conectado dos computadores sobre uma plataforma que permite diversas ações gestuais (Canavilhas \& Rodrigues, 2017). Assim, métodos oriundos da informática são incorporados, sobretudo no estudo da experiência do usuário (ux, em inglês) e interfaces.

Boa parte destas estratégias parte de abordagens ao redor do objeto ou trilha um caminho que requer do usuário uma reconstrução dos seus hábitos, não uma captura direta de dados e informações. Apesar da possibilidade de monitoramento dos dispositivos, algumas vezes realizada de maneira deveras problemática (Macaskill \& Dance, 2013), é preciso realizar isto de uma maneira que compreenda as variáveis novas do meio e ainda respeite a privacidade do cidadão.

Este relato metodológico parte deste princípio. Durante o ano de 2016, foi desenvolvida uma nova estratégia de pesquisa para verificação de audiência em tempo real, resultando em dados depurados para uma segunda etapa de trabalho realizada através de entrevista, amparada por dinâmicas de facilitação gráfica. Conforme será apresentado posteriormente, o trabalho parte de uma perspectiva que busca não apenas compreender um novo cenário, mas também novas formas de apropriação da informação.

Ao longo dos meses, dados sobre aplicativos utilizados, hora de uso e estado da conexão, entre outros, foram registrados. Todos os participantes da pesquisa receberam um aparelho de maneira gratuita e foram informados sobre as práticas de registro, conforme orientações dos comitês de ética da instituição. Apesar deste conhecimento, não foram observados quais websites foram visitados ou discussões realizadas através das redes sociais. Isto concede um grau importante de liberdade para o usuário, apesar de um contexto monitorado. Cabe ressaltar que mesmo ciente disso, o grupo teste não mostrou preocupação avançada com tais premissas, com interesse principal no ato de receber um aparelho novo.

A compreensão da trajetória deste trabalho, portanto, requer um resgate do cenário, para posterior ampliação dos seus horizontes. Por fim, os passos são discutidos, resultando em uma nova possibilidade de pesquisa em Comunicação Social.

\section{Contextualização}

Após estes 10 primeiros anos, o imaginário sobre o que poderia ser a Internet Móvel foi reconstituído através do IPhone, um aparelho desenhado desde o começo para este fim. Os aparatos para acesso em mobilidade até esta data ou vinham da telefonia, com o uso da voz como foco principal, ou de computadores pessoais, como os Microsoft Pocket Pc. Os conceitos trabalhados por Rheingold (2003) e Levinson (2004) puderam tomar forma com a popularização não só dos aparelhos, mas também das redes, que forma a infra-estrutura necessária para que o sistema funcione. Ficou claro neste momento que a Internet Móvel não era uma reprodução tácita dos formatos de internet no PC, mas sim um campo que se abria para novas formas de comunicação em rede.

Um dos principais pontos deste novo modelo foi o fato dos indivíduos estarem always-on, conforme Pellanda (2005), ou seja, conectados de forma permanente à rede. Neste ponto, a conversação social não mais era interrompida, assim como o fluxo de informações do indivíduo para o resto da rede, e da rede para o indivíduo. Além do tempo, a questão do espaço também era reconfigurada, pois o usuário da rede transita em movimento pela cidade, formando uma nova significação, como salienta Mitchell (2003). 


\section{DISERTACIONES}

ESTUDIOS

Comunicación y dispositivos móviles

ISSN: $1856-9536$

Doi:

Volumen 12, Número 1 / Enero-junio 2019

Versión PDF para imprimir desde

http://revistas.urosario.edu.co/index.php/disertaciones

O smartphone então se tornou o principal ícone da Internet Móvel e está conectado de diversas formas com o cotidiano de diferentes formas. Um exemplo claro disso é o modo como os refugiados ${ }^{1}$ da África na Europa dependem deste meio de comunicação para continuar em contato com suas famílias nos países de origem. Este é um exemplo extremo de como a Internet Móvel é persuasiva e ubíqua em diferentes cenários da contemporaneidade.

Mesmo com todas estas características, a Internet Móvel vem sendo entendida e quantificada pelas mesmas formas de monitoramento da Internet desktop, que por sua vez traz heranças das mídias analógicas. Neste sentido, o Ubilab iniciou esta pesquisa, que visa justamente buscar uma metodologia para entender os usos desta forma de comunicação em seu devido contexto.

Paralelo a este trabalho, no cenário acadêmico nacional, os métodos que partem da criação de ferramentas ou da captura de dados no contexto de uso dos dispositivos móveis não são comuns. A partir da revisão bibliográfica dos últimos cinco anos de trabalhos do Congresso Brasileiro de Ciências da Comunicação (Intercom) e do Encontro da Associação Nacional dos Programas de Pós-Graduação em Comunicação (Compós), assim como das teses e dissertações presentes no repositório da Coordenação de Aperfeiçoamento de Pessoal de Nível Superior (Capes) e também de artigos indexados no Google Acadêmico, é possível perceber a centralidade da pesquisa brasileira em métodos prioritariamente ou exclusivamente qualitativos no que tange os dispositivos móveis. A busca realizada nestes repositórios a partir de palavras-chave como mobile, móvel, móveis, smartphone, smartphones, celular, metodologia e método evidenciou também a atualidade deste tópico de pesquisa, uma vez que os resultados foram em sua maioria de trabalhos a partir do ano de 2015.

Percebe-se que os olhares, quando se investiga os dispositivos móveis, neste caso, especialmente os celulares e smartphones, concentram-se sobretudo na análise de produtos publicados e através de métodos que observam o uso destes pela audiência (a partir de entrevistas ou observações em contextos controlados), não realizando um trabalho de produção de ferramentas específicas de análise. Neste sentido, os métodos prioritários costumam estar centrados em revisões teóricas (Fonseca \& Barbosa, 2016; Mosimann, 2015), estudo de caso (Pipano, 2016; Nicolau, 2015), entrevista (Felippi et al., 2017), cartografia móvel (Malini, 2016; Recuero, 2016; Calmon \& Antoun, 2014), etnografia móvel (Henriques, 2016; Henriques \& Furini, 2017), media ecology (Dall'Agnese \& Barichello, 2017) e questionários (Felippi et al., 2017).

Outros tipos de abordagens quantitativas, ainda que sem a produção de ferramenta própria, podem ser encontradas de certa maneira nas análises de redes sociais digitais, ao utilizar softwares para captura, classificação, análise e representação visual de conversações online (Recuero, 2012; Recuero et al., 2014; Recuero et al., 2015). Assim, metodologias como estudos de caso, entrevistas, cartografias e etnografias, além do uso de softwares para análise estrutural de redes sociais acompanhada de análise de conteúdo estão consolidadas. Elas indicam caminhos relevantes para captura e obtenção de dados em rede, válidas também para investigações que utilizam os termos mobile, móvel ou mobilidade, ou smartphone e celular, relacionados a alguma metodologia.

Entre estes trabalhos e pesquisa em âmbito nacional, vale destacar também a atuação perene e pertinente da Faculdade de Comunicação da Universidade Federal da Bahia (Barbosa \& Palacios, 2018; Palacios et al., 2014; Lemos, 2013). A pesquisa sobre dispositivos móveis concentra foco na análise de aplicativos e publicações veicu-

1 https://qz.com/500062 


\section{DISERTACIONES}

ESTUDIOS

Comunicación y dispositivos móviles

ISSN: $1856-9536$

Doi:

Volumen 12, Número 1 / Enero-junio 2019

Versión PDF para imprimir desde

http://revistas.urosario.edu.co/index.php/disertaciones

ladas nestes aparelhos também observando o papel dos elementos presentes nestas interações. $O$ trabalho reverbera em iniciativas em Portugal, e também na Universidade Federal da Paraíba (Silva \& Nunes, 2016).

Enquanto na comunicação social são estudados fenômenos humanos, áreas mais exatas focam no estudo de ferramentas de captura para estes dados, como em Kronbauer (2013). Este é um dos poucos registros alinhados com a proposta apresentada neste artigo.

\section{Para compreender o uso do smartphone}

A importância de monitorar os usuários de smartphones das classes C e D está em entender seu comportamento, bem como seus limites relacionados ao uso de $3 \mathrm{G} \mathrm{e} \mathrm{4G}$, bateria, memória e demais fatores apresentados neste artigo. Segundo Fidalgo et al. (2013), "as rotinas de consumo, como, por exemplo, o armazenamento na nuvem, a sincronização entre os dispositivos móveis (coordenar a experiência e a sequência de utilização), assim como a ubiquidade e a mobilidade física, colocam os dispositivos móveis no centro da gravidade de consumo multi telas". Compreender este cenário por meio do ponto de vista do usuário, possibilita maior precisão no desenvolvimento de novas apps e funções, e melhora a experiência com o dispositivo.

Bennet (2011) e Carnegie (2002) destacam os diferentes níveis da relação entre o usuário e a tecnologia: da origem à construção da intimidade tecnológica, o que representa a identificação da relação física e emocional entre o usuário e um sistema tecnológico. $\mathrm{O}$ constante monitoramento e análise de dados recolhidos permite um entendimento detalhado do processo de utilização diária do smartphone e uma definição de perfil do usuário. A união das técnicas é complementar e essencial para o resultado.

De acordo com Wei (2007), existem algumas características específicas dos telefones móveis que o tornam um desafio ao ter seu uso estudado, como seu tamanho e tela pequenos, a mobilidade do usuário, os diferentes ambientes em que o usuário pode se encontrar, a variedade de atividades que são possíveis e a probabilidade de o usuário estar realizando outras tarefas enquanto utiliza estes dispositivos, como caminhar, conversar e carregar coisas. Por isso, a autora afirma que métodos inovadores são necessários para estudar o uso de telefones móveis de maneira efetiva. Sendo assim, ela conduziu uma revisão de literatura para identificar as metodologias existentes, as quais ela categoriza em três gêneros:

- Métodos clássicos de pesquisa: como observação, entrevistas e grupos focais para coleta de dados (pesquisa qualitativa). A observação do uso de dispositivos móveis, entretanto, pode ser um pouco complicada por causa do tamanho da tela do dispositivo e porque, neste caso, a conversa que é 'ouvida' é unilateral. Entrevistas e grupos focais podem minimizar este problema, mas geralmente requerem que o participante relembre e sintetize seu comportamento, o que pode acabar sendo tendencioso ou generalizado.

- Diários: para solucionar problemas de memória e acurácia dos dados coletados, alguns pesquisadores pediram para participantes escreverem diários em vários formatos (papel ou digital/voz). É possível utilizar o GPS do dispositivo para identificar mudanças na localização do usuário e disparar questionários para o usuário completar naquele local, fornecendo, assim, detalhes dos aspectos mais pessoais do uso do dispositivo que não podem ser facilmente observados.

- Registro automatizado por computadores ou gravação de comportamentos por câmeras: alguns pesquisadores combinaram os relatos dos participantes com dados reais de cobrança e uso dos dispositivos dos 


\section{DISERTACIONES}

ESTUDIOS

Comunicación y dispositivos móviles

ISSN: $1856-9536$

Doi:

Volumen 12, Número 1 / Enero-junio 2019

Versión PDF para imprimir desde

http://revistas.urosario.edu.co/index.php/disertaciones

provedores de serviço. Também é possível coletar dados a partir de pequenas câmeras acopladas aos dispositivos para gravar as atividades em telas e teclados, expressões nas faces dos usuários, ambientes ao redor, etc. Desta forma, os usuários ficam livres para usar o dispositivo naturalmente e, ao mesmo tempo, é possível capturar detalhes e ações específicas sem a necessidade de ter um observador por perto para fazer perguntas. Entretanto, estes métodos podem intimidar um pouco o participante, que acaba perdendo um pouco da sua privacidade. Além disso, cabos e equipamentos intrusivos podem causar certo constrangimento em determinadas situações, como na interação com o dispositivo em locais públicos.

Wei (2007) destaca que é necessário considerar a configuração cultural em que a pesquisa está inserida na hora de escolher os métodos a serem utilizados e que, em alguns casos, pode ser interessante fazer uma combinação de métodos para um estudo efetivo do uso de dispositivos móveis, a fim de compensar os pontos fortes e fracos de cada um.

Seo et al. (2016) desenvolveram um sistema para identificar o comportamento de pessoas que estão assistindo Tv. Esta, segundo os autores, é uma tarefa complexa, pois as pessoas realizam várias outras atividades depois de ligar o aparelho, como caminhar pela casa, usar um smartphone e realizar tarefas domésticas. Por isso, é necessário saber não apenas se a tv está ligada, mas também se os espectadores estão de fato prestando atenção nos programas que estão passando. Sendo assim, compreender o contexto destas pessoas poderia ajudar a medir o seu real engajamento e, assim, possibilitaria a entrega de um serviço personalizado. 0 sistema desenvolvido pelos autores utiliza dados de RSSI e dos sensores acelerômetro e giroscópio de smartwatches para monitorar as atividades dos usuários e detectar se eles estão localizados na zona da tv. Além disso, são coletados dados sobre uso de aplicativos no smartphone para identificar o que os usuários estão de fato fazendo enquanto estão na zona da Tv.

\section{Relato da Pesquisa}

A proposta de uma metodologia precisa e especialmente pensada para o contexto móvel foi dividida em etapas. Iniciada em 2016 e ainda em andamento, a pesquisa é liderada pelo Laboratório de Mobilidade e Convergência Midiática (UBILAB) da Faculdade de Comunicação da PUCRs. ${ }^{2}$ A investigação teve como objetivo o entendimento de uso e contexto da comunicação móvel, partindo da premissa de que dados isolados sobre aplicativos específicos e ou investigações de uso em ambientes controlados não necessariamente refletiam o real uso dos dispositivos e de seus aplicativos. Além disso, estes cenários controlados ignoravam as limitações do dia a dia do consumo mobile, principalmente em um país em desenvolvimento como o Brasil. Entre as limitações que podem influenciar o consumo em um ambiente não controlado e que não são visíveis em teste de usabilidade, por exemplo, estão: a memória limitada dos aparelhos, a limitação da internet móvel (seja por créditos ou cobertura de sinal) o consumo de bateria durante o dia, entre outros.

Observou-se que as particularidades da comunicação móvel exigiam métricas para além das ferramentas de contagem de visualizações e sessões de cada app ou mesmo de pesquisas de institutos especializados que englobam a quantidade, muitas vezes sem tanta ênfase em dados contextuais e/ou análises qualitativas deste consumo

2 http://www.ubilab.com.br 


\section{DISERTACIONES}

ESTUDIOS

Comunicación y dispositivos móviles

ISSN: $1856-9536$

Doi:

Volumen 12, Número 1 / Enero-junio 2019

Versión PDF para imprimir desde

http://revistas.urosario.edu.co/index.php/disertaciones

móvel. Em uma estratégia de polinização, ${ }^{3}$ outros meios foram observados e, entre eles, uma analogia com ferramentas de mensuração televisiva se mostrou apropriada: os aparelhos de mensuração de audiência da televisão adentram o ambiente cotidiano de consumo desta mídia. E se este consumo móvel fosse também mensurado no próprio contexto de uso da audiência?

Para tanto, era preciso investigar viabilidades e escolher um sistema operacional para iniciar a pesquisa. Desta forma, tendo em vista a maior penetração do sistema operacional Android, e também questões técnicas, escolheu-se este para ser a base de teste da metodologia. A partir disso, elaborou-se um software que capturasse os dados de usuários e os enviasse a uma base de dados para análise dos pesquisadores. Estes dados coletados consistem em comportamentos relativos ao uso de aplicativos, tipo de conexão, uso de bateria e localização. Através da base de dados, foi possível filtrar e cruzar os resultados para diferentes tipos de visualização e entendimento. Decidiu-se também aplicar esta pesquisa em um grupo controlado de participantes que receberam gratuitamente um novo smartphone.

O modelo escolhido foi baseado em popularidade, especificações técnicas que viabilizassem consumos e produção multimídia, mas que ainda, tivesse especificações técnicas populares, ou seja, com limitadores comuns a muitos usuários brasileiros. Para tanto, foi escolhido o modelo Moto G3, com 8 GB de memória e 8 GB de cartão de memória externo.

Já o grupo selecionado possibilitou a validação da precisão dos dados e análises qualitativas de aceitação, consumo e outras observações. Todos os usuários participantes ganharam um aparelho financiado pela pesquisa. Neste aparelho o aplicativo de coleta já estava instalado, com um ID específico para cada usuário. Importante mencionar que nenhum dado pessoal do usuário foi capturado, tampouco conteúdos de mensagens, senhas ou mesmo endereços de URL.

Assim, a pesquisa foi dividida nas seguintes etapas:

1. Comprar aparelhos para doação: foram adquiridos para a pesquisa 20 aparelhos para doação. Destes celulares, um ficou para os desenvolvedores, um para testes da equipe e um para o caso de problema técnico ou perda.

2. Desenvolver um app de monitoramento: uma empresa terceirizada desenvolveu o aplicativo e orientou quanto às formas de monitoramento.

3. Selecionar os participantes: todos os participantes selecionados tinham algum grau de proximidade com os pesquisadores.

4. Aferir a confiabilidade dos dados: para que a pesquisa fosse realizada com sucesso, a confiabilidade dos dados recebidos seria essencial.

5. Monitorar os participantes: os participantes foram monitorados, a fim de compreender peculiaridades na forma de uso.

6. Entrevista em profundidade com extremos da amostra: os participantes que mais se destacaram no uso, foram selecionados como amostra para uma entrevista e dinâmica com cards.

3 Wilkinson (2016) conceitua como polinizadores empreendedores capazes de observar algo em um segmento e aplicar em outra área. 
Os dados foram coletados num total de dois meses, sendo transmitidos para uma base de dados sempre que o usuário se conectava a uma conexão do tipo wi-fi (figura 1). No total, nesta primeira etapa da pesquisa, foram monitorados 1270 horas ativas, um total de 130 apps utilizados pelos usuários, com pouco mais de 11800 registros de usos de apps. Entre as regras de contabilização dos dados, é importante ressaltar que, nas capturas de tempo de uso do app, observamos o uso efetivo. Não foi capturado o tempo em background.

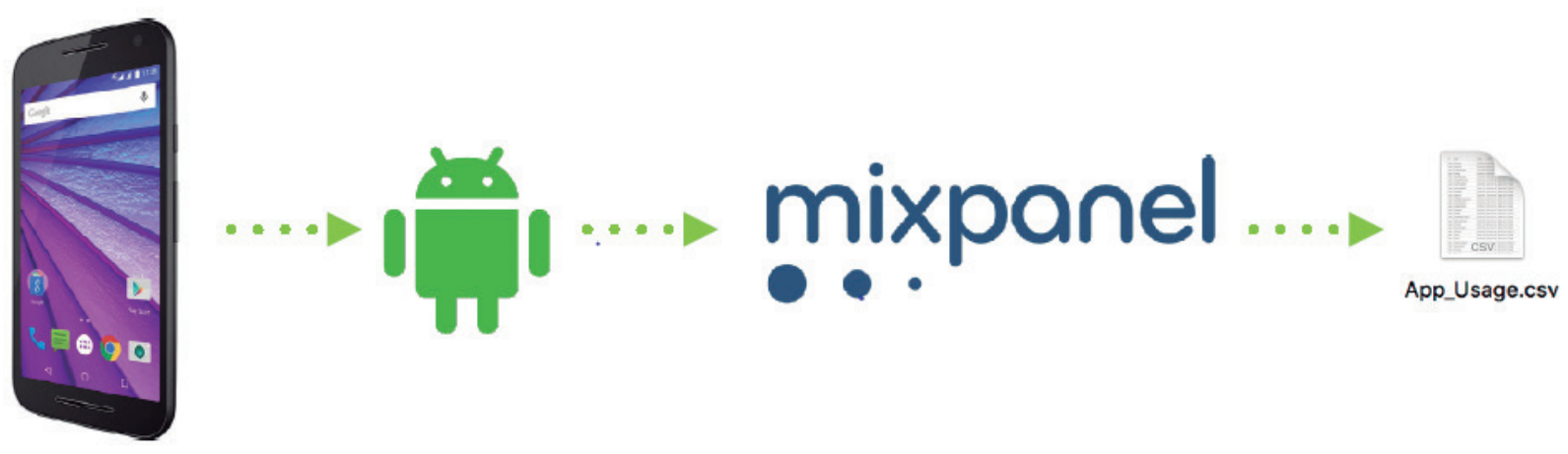

Figura 1. Funcionamento da metodologia de captura de dados

Fonte: montagem dos autores (2017).

Após a captura dos dados, foram selecionados alguns participantes cujos dados coletados se destacaram dos demais. Estes participantes foram entrevistados em profundidade, com uma dinâmica individual dividida em duas partes. A primeira, consistia em o usuário listar a ordem do que para ele era mais limitador em relação ao uso do seu aparelho (figura 2). As opções disponíveis foram:

- conexão 3G/4G (conexão móvel);

- $\quad$ wi-fi (conexão banda larga);

- bateria (maior duração de tempo de uso);

- tamanho da tela (resolução e tamanho da tela);

- memória (armazenamento de dados);

- câmera (resolução da câmera). 


\section{DISERTACIONES}

ESTUDIOS

Comunicación y dispositivos móviles

ISSN: 1856-9536

Doi:

Volumen 12, Número 1 / Enero-junio 2019

Versión PDF para imprimir desde

http://revistas.urosario.edu.co/index.php/disertaciones

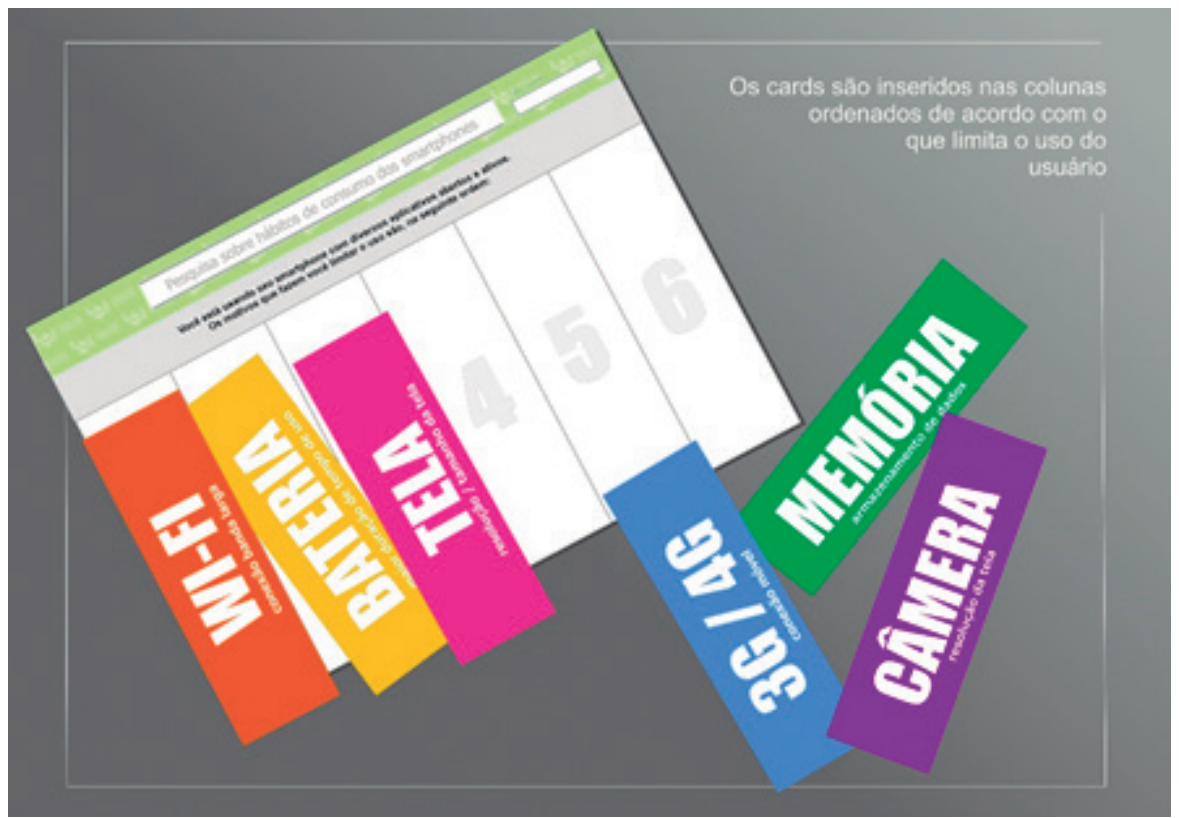

Figura 2. Parte 1 da entrevista em profundidade - limitações em ordem de prioridade Fonte: os autores (2017).

A outra, consistia em o usuário elencar nas colunas, quais aplicativos ele:

- já tem acesso;

- quais ele já teve (mas não tem mais);

- quais ele não tem mais acesso;

- quais ele planeja ter;

- quais ele não pensa em obter.

Nesta etapa, foram oferecidos cards correspondentes aos aplicativos pagos mais populares no Brasil, em termos de uso, e aplicativos de mídia (jornais e vídeo on demand), além de aplicativos gratuitos, mas que requerem cartão de crédito. As opções oferecidas foram:

- Cabify;

- Spotify;

- Netflix;

- Uber;

- Now tv;

- Telecine Premium;

- Claro tv;

- Globo Sat;

- Kindle/Kobo;

- Jornal por assinatura (card genérico); 
- Utilitário - editor de texto/imagem, notas, mensagem, email, segurança, localização (card genérico).

Adicionalmente aos aplicativos já elencados, cinco cards em branco foram disponibilizados para que, caso algum aplicativo importante não estivesse entre os cards disponibilizados, o usuário participante pudesse escrever e incluir em alguma das colunas (figura 3).

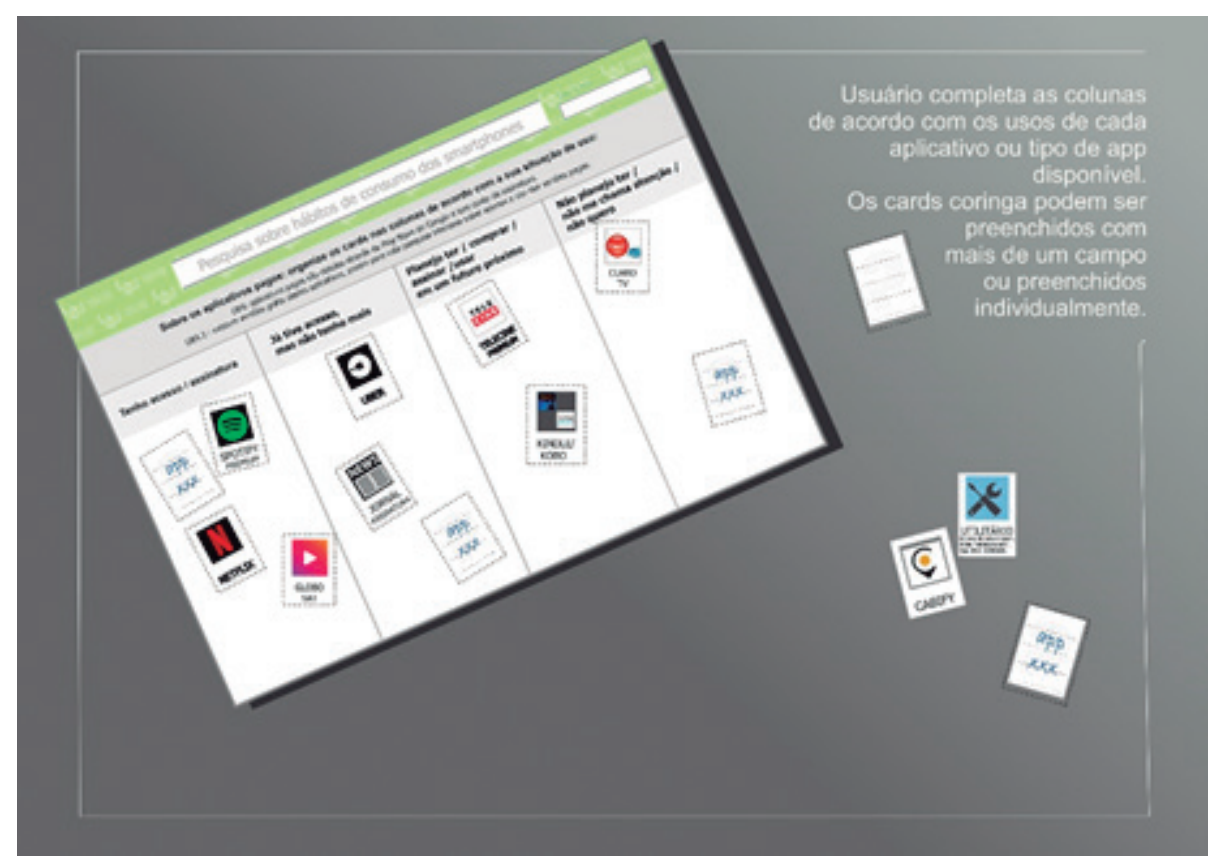

Figura 3. Parte 2 da entrevista em profundidade - acesso a apps pagos

Fonte: os autores (2017).

Esta etapa da dinâmica teve como objetivo entender aspectos qualitativos, uma vez que a informação do consumo destes aplicativos via smartphone por cada usuário já eram de conhecimento da equipe através do monitoramento de dados. 0 monitoramento indicava o uso/acesso a apps, mas não o motivo de não acesso, nem o desejo futuro de ter acesso a certos apps. Além disso, saber se o usuário já teve acesso a estes apps e deixou de ter, evidenciando os motivos, também traria informações complementares quanto ao uso de smartphones no contexto brasileiro, de forma qualitativa.

Em um terceiro momento, foi feita a análise de todos os dados. Para tanto, na análise, foram elaborados perfis que detalhavam a forma de uso e comportamento de usuários, de acordo com seu padrão de uso consumo durante o período. $O$ gráfico foi elaborado a partir dos aplicativos mais utilizados pelo usuário, informando também o percentual em relação ao total de acessos que estes representavam. A visualização gráfica se mostrou adequada para correlacionar visualmente diferentes aspectos do consumo de cada pesquisado. 0 gráfico da figura 4 detalha os períodos do dia, mostrando:

- a intensidade dos aplicativos mais acessados em cada turno (quanto maior intesidade, maior o tamanho do aplicativo indicado no gráfico); 
- a intensidade do uso de tipo de conexão e carga de bateria (quanto maior a intensidade, maior o tamanho do uso de tipo de conexão e carta de bateria).

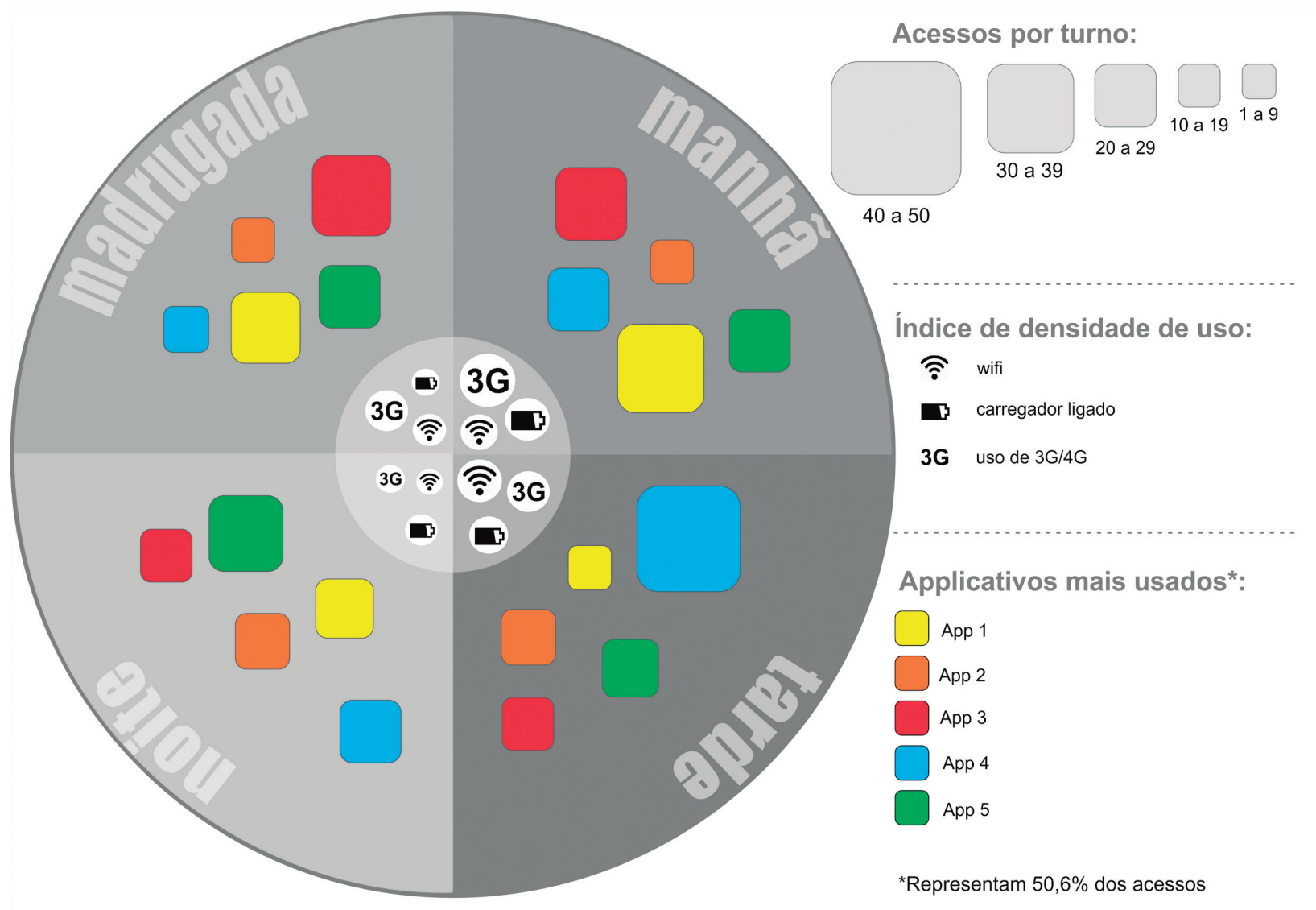

Figura 4. Exemplo de visualização de dados

Fonte: os autores (2017).

Esta foi uma pesquisa inédita e que trouxe dados diferenciados sobre usuários, de forma qualitativa. Diferente das dos dados trazidos por empresas coletoras informações quantitativas, esta pesquisa conseguiu reunir tanto informações gerais durante a coleta, como também compreender peculiaridades do uso de um grupo de usuários participantes. Isto mostrou que, por si só, cada um tem um motivo para utilizar o seu aparelho smartphone da maneira que lhe convém. Apesar de todos pertencerem a uma mesma classe social, possuírem padrões de vida parecidos e serem de uma mesma geração, cada qual executa ações de forma diferenciada e bastante personalizada, em modelo de aparelho que é comum a todos. 


\section{DISERTACIONES}

ESTUDIOS

Comunicación y dispositivos móviles ISSN: $1856-9536$

Doi:

Volumen 12, Número 1 / Enero-junio 2019

Versión PDF para imprimir desde

http://revistas.urosario.edu.co/index.php/disertaciones

\section{Considerações Finais}

A proposta desta primeira etapa da pesquisa, detalhada até o momento, não foi esgotar as respostas e entendimentos de uso dos pesquisados (uma vez que a investigação ainda está em andamento), mas sim, validar a metodologia estabelecida. Uma metodologia criada a partir especificamente das particularidades da comunicação móvel via smartphones. Cada meio traz uma bagagem cultural, técnica e física e corporal, como já afirmava Chartier (1998, p. 16) quando da popularização da leitura nos computadores.

Com o computador, a mediação do teclado, que já existia com a máquina de escrever, mas que se amplia, instaura um afastamento entre o autor e seu texto. A nova posição de leitura, entendida num sentido puramente físico e corporal ou num sentido intelectual, é radicalmente original: ela junta, e de um modo que ainda se deveria estudar, técnicas, posturas, possibilidades que, na longa história da transmissão do escrito, permaneciam separadas (Chartier, 1998, p. 16).

Se os computadores, ao se popularizarem, requisitaram investigações específicas do seu consumo, quais seriam estas peculiaridades da comunicação móvel? Esta investigação se propôs a entender algumas dessas particularidades, partindo da premissa de que um novo meio exige nova metodologia e que suas peculiaridades residem em aspectos como:

- um novo contexto físico de local (móvel);

- uma nova postura corporal (completamente diferente dos computadores ou mesmo do papel);

- limitações técnicas específicas de um aparelho que acompanha o dia de um usuário como: bateria, conectividade, fragmentação de uso e multitasking, memória, especificações da câmera e tamanho da tela.

A partir destas premissas, a pesquisa capturou dados dos usuários para compreender de forma qualitativa e preliminar o uso de smartphones por seus usuários, bem como o comportamento dos mesmos. Já foi possível identificar usuários que denotam comportamentos ímpares e que não poderiam ser verificados de forma isolada por parâmetros específicos - como usos de determinado aplicativo, ou questões relacionadas ao aparelho de determinado fabricante. 0 conjunto dos dados capturados, bem como a liberdade fornecida ao usuário no que tangia a download e uso de aplicativos, mobilidade, tipo de conexão e carga de bateria fizeram o diferencial nesta primeira etapa da pesquisa. Isto permitiu verificar que existem formas de gerenciamento de sistema para usos de bateria e conexão que não seriam os usuais esperados pelos fabricantes de aparelhos e desenvolvedoras de aplicativos.

Quanto aos usos, o usuário teve total liberdade para escolher seus aplicativos. Sabe-se que, pelo fato de o usuário saber que estava participando de uma pesquisa, poderia limitar suas escolhas de apps baixados. Interessante que, apesar de pertencerem a uma mesma faixa de idade, perfil socioeconômico e proximidade geográfica, as escolhas foram bastante diversificadas, mesmo com uma predominância de apps populares, em especial os de redes sociais. Isto deixou também uma lacuna para um entendimento, talvez, em maior escala para encontrar predominância de perfis de usuários. Ou seja, grupos de usuários que possuam formas de usos e comportamentos em comum. Percebe-se que as possibilidades da pesquisa ainda são maiores do que os resultados previamente encontrados. 


\section{DISERTACIONES}

ESTUDIOS

Comunicación y dispositivos móviles

ISSN: $1856-9536$

Doi:

Volumen 12, Número 1 / Enero-junio 2019

Versión PDF para imprimir desde

http://revistas.urosario.edu.co/index.php/disertaciones

O método apresentado aqui concretiza também uma virada particular do laboratório em si. Após anos de pesquisas realizadas através das mais diversas maneiras, esta marca o desenvolvimento de um método que dialoga com a Ciência da Computação para desenvolver um aplicativo próprio. Suas demandas partiram de um estudo das permissões que o sistema operacional oferece para posteriormente definir as características prioritárias do novo software. Este processo necessita de maior tempo para execução, pois há uma sequência de estudos prévios e tempo de teste da ferramenta, porém oferece resultados conforme interesses específicos da investigação e uma independência das criações de outros desenvolvedores.

Assim, a análise do caminho empírico percorrido mostrou o seu tom inovador na sua natureza e combinação de estratégias, além da viabilidade da estratégia. Além do encaminhamento dos resultados, indicado anteriormente, este método ainda revelou outros limites inesperados.

Como observado anteriormente, foi necessária uma combinação de técnicas de comunicação com a construção de um aplicativo dedicado para esta finalidade. Isto demandou um diálogo com produtores de aplicativos no sistema Android e constantes atualizações, em virtude de uma troca de versão do sistema que ocorreu durante o processo e limitou funções de versões anteriores do software.

Os telefones foram pré-configurados antes da entrevista inicial de entrega para os 17 usuários, pois deveriam inicializar sua operação e desaparecer da tela inicial dos aparelhos. No ato da entrega, a primeira surpresa ocorreu. Ao passo que a equipe do laboratório preparou documentos e rotinas para manter as guias éticas do processo, apenas uma das 17 pessoas solicitou mais informações sobre o que iria ocorrer com os dados. Ao passo que isto decorre de explicações que incluíam uma amostra de testes de captura para mostrar como o trabalho preservava suas identidades e o teor da comunicação realizada (não mostrar o conteúdo de mensagens, por exemplo), a equipe imagina que boa parte do grupo estava interessada, sobretudo, na obtenção de um aparelho sem o dispêndio financeiro.

Outro ponto foi a necessidade de constante monitoramento dos aparelhos. Mesmo que rotinas automatizadas permitam a fluidez dos processos sem a intervenção dos agentes humanos, pesquisas experimentais como esta demandam a observação, pois os usuários estão agindo sobre um sistema. Isto ocorre não apenas pelas atualizações do aparelho, mas o constante processo de instalar e utilizar novos aplicativos.

Este processo inicial resultou em dados que indicaram como os usuários de telefones celulares pouco a pouco deixam de falar em seus aparelhos para utilizar redes sociais e aplicativos de mensagens instantâneas. A intensidade da visualização de vídeos foi deveras interessante, ilustrando na prática como o tamanho da tela parece não ser problema para um público disposto a ver o conteúdo conforme a sua preferência e sob demanda. A principal limitação indicada pelo grupo foi a capacidade de armazenamento do aparelho, fato que reforça a necessidade do comunicador de compreender as dinâmicas deste novo espaço de busca da atenção do público.

Portanto, este método segue em utilização, porém em uma nova fase e com novas funcionalidades. Elas decorrem da abordagem inicial relatada neste artigo, expandidas para novos aparelhos, porém com escopo maior e outras dinâmicas de entrevista. Desta forma, acreditamos ser possível construir novos caminhos para compreender novos espaços e manifestações da sociabilidade e comunicação contemporâneas. 


\section{DISERTACIONES}

ESTUDIOS

Comunicación y dispositivos móviles ISSN: $1856-9536$

Doi:

Volumen 12, Número 1 / Enero-junio 2019

Versión PDF para imprimir desde

http://revistas.urosario.edu.co/index.php/disertaciones

\section{Referências}

1. Barbosa, S., \& Palacios, M. (2018). La experiencia con la investigación teórica y aplicada sobre el periodismo convergente y la movilidad en el Proyecto Laboratorio de Periodismo Convergente. Interin (UTP), 23, 256-276.

2. Bardin, L. (2011). Análise de conteúdo (11ª ed.). Lisboa: Edições 70.

3. Calmon, P., \& Antoun, H. (2014). Expressões ninjas: uma cartografia da \#mídianinja nas redes sociais. Anais do XIX Congresso de Ciências da Comunicação na Região Sudeste, Vila Velha, sP, Brasil.

4. Canavilhas, J., \& Rodrigues, C. (Orgs.). (2017). Jornalismo móvel: linguagem, géneros e modelos de negócio. Covilhã: LabCom Books.

5. Chartier, R. (1998). A aventura do livro: do leitor ao navegador. São Paulo: UnESP.

6. Dall'Agnese, C. T. W., \& Barichello, E. M. da R. (2017). Media ecology: abordagem contextual para o estudo das narrativas jornalísticas transmídia. Anais do XVIII Congresso de Ciências da Comunicação na Região Sul, Caxias do Sul, RS.

7. Felippi, Â., \& Escosteguy, A. C. (junho, 2017). Os usos do celular no rural brasileiro contemporâneo: jovens e novas formas de sociabilidade. Anais do XXVI Encontro Anual da Compós, São Paulo, RS, Brasil.

8. Fidalgo, A., Serrano Tellería, A., Carvalheiro, J. R., Canavilhas, J., \& Correia, J. C. (2013). El ser humano como portal de comunicación: la construcción del perfil en el teléfono móvil. Revista Latina de Comunicación Social.

9. Fonseca, A., \& Barbosa, S. (2016). Affordances indutoras de inovação no jornalismo móvel de revistas para tablets. Intexto. Anais do XXV Encontro Anual da Compós, Universidade Federal de Goiás, Goiânia, Brasil.

10. Fragoso, S., Recuero, R., \& Amaral, A. (2011). Métodos de pesquisa para internet (1 ${ }^{\text {a }}$ ed.). Porto Alegre: Sulina.

11. Henriques, S. (2016). Etnografia móvel: uma proposta metodológica para os estudos da mobilidade na comunicação (Tese de doutorado, Pontifícia Universidade Católica do Rio Grande do Sul, Porto Alegre, RS, Brasil).

12. Henriques, S., \& Furini, L. (2017). Etnografia móvel: um estudo da mobilidade da informação na votação da PEC 171. Comunicação \& Inovação, 18(36), 114-127.

13. Kozinets, R. (2009). Netnography: doing ethnographic research online. Londres: SAGE.

14. Kronbauer, A. (2013). Um modelo de avaliação de usabilidade de aplicativos para smartphones baseado na captura automática de interações com o usuário (Tese de doutorado, Universidade Federal da Bahia, Salvador, BA, Brasil).

15. Lemos, A. (2013). A comunicação das coisas. Teoria ator-rede e cibercultura (1ª ed.). São Paulo: Annablume.

16. Levinson, P. (2004). Cellphone (1 $1^{\mathrm{a}}$ ed.). New York: Palgrave.

17. MacAskill, E., \& Dance, G. (2013). NSA files: decoded. Disponível em https://www.theguardian.com/world/ interactive/2013/nov/01/snowden-nsa-files-surveillance-revelations-decoded\#section/1 


\section{DISERTACIONES}

ESTUDIOS

Comunicación y dispositivos móviles

ISSN: $1856-9536$

Doi:

Volumen 12, Número 1 / Enero-junio 2019

Versión PDF para imprimir desde

http://revistas.urosario.edu.co/index.php/disertaciones

18. Malini, F. (junho, 2016). Um método perspectivista de análise de redes sociais: cartografando topologias e temporalidades em rede. Anais do $25^{\circ}$ Encontro Anual da Associação Nacional de Programas de Pós-Graduação em Comunicação, Goiânia, Go.

19. Mitchell, W. J. (2003). ME++, the cyborg self and the networked city. Boston: MIT Press.

20. Mosimann, R. (junho, 2015). Smartphones, internet móvel e transformações na comunicação. Considerações sobre este processo no Brasil e na Argentina. Anais do XXXVIII Congresso Brasileiro de Ciências da Comunicação, Rio de Janeiro, RJ, Brasil.

21. Nicolau, M. (junho, 2015). No emaranhado das redes: do 'individualismo conectado' à interacionalidade transversal pelo celular. Anais do Encontro Anual da Associação Nacional de Programas de Pós-Graduação em Comunicação.

22. Palacios, M., Barbosa, S., Silva, F., \& Cunha, R. (2014). Aplicativos jornalísticos vespertinos para tablets. Cartografia do fenômeno ante o desafio de uma produção original e inovadora. Sur Le Journalisme, 3, 40-55.

23. Pellanda, E. C. (2005). Internet móvel: novas relações na cibercultura derivadas da mobilidade na comunicação (PhD thesis ed.). Porto Alegre: Pontifical Catholic University of Rio Grande do Sul.

24. Pipano, I. (junho, 2016). Espelhos opacos, espelhos reflexos: selfies e autorrepresentação na era dos smartphones. XXV Encontro Anual da Compós, Universidade Federal de Goiás, Goiânia.

25. Recuero, R. (2012). A conversação em rede: a comunicação mediada pelo computador e as redes sociais na internet ( $1^{\mathrm{a}}$ ed.). Porto Alegre: Sulina.

26. Recuero, R. (2016). Métodos mistos: combinando etnografia e análise de redes sociais em estudos de mídia social. In B. Campanella \& C. Barros. (Orgs.), Etnografia e consumo midiático: novas tendências e desafios metodológicos (1 ${ }^{\mathrm{a}}$ ed.) (pp. 117-132). Rio de Janeiro: E-Papers.

27. Recuero, R., Zago, G., \& Bastos, M. (2014). O discurso dos \#ProtestosBR: análise de conteúdo do Twitter. Galáxia (São Paulo), 14(28), 199-216.

28. Recuero, R., Zago, G., Bastos, M., \& Araújo, R. (2015). Hashtags functions in the protests across Brazil. Londres: SAGE Open.

29. Rheingold, H. (2003). Smart mobs. Cambridge: Perseus Publishing.

30. Rogers, R. A. (2013). Digital methods. Cambridge: мiт Press.

31. Seo, J., Yun, H., Lim, H., Suh, B., Oh, C., \& Lee, J. (2016). A system designed to collect users' tv-watching data using a smart TV, smartphones, and smart watches. Proceedings of the ACM International Conference on Interactive Experiences for TV and Online Video, Chicago.

32. Silva, F. F., \& Nunes, P. (2016). Jornalismo, ética, mobilidades e narrativas transmídias. Âncora - Revista Latino-Americana de Jornalismo, 3, 9-13.

33. Wei, C. Y. (2007). Capturing mobile phone usage: research methods for mobile studies. Professional Communication Conference, Seattle.

34. Wilkinson, A. (2016). O código dos criadores: as seis habilidades essenciais dos grandes empreendedores. São Paulo: HSM do Brasil. 